\title{
Spontaneous (accidental) hypothermia in the elderly
}

\author{
FREDERICK H. ROHLES, JR. \\ Institute for Environmental Research, Kansas State University, Manhattan, Kansas 66506
}

\begin{abstract}
Oral temperatures were taken under field conditions on 730 elderly persons whose ages ranged from 60 to 94 years. The mean temperature of the sample was $36.4^{\circ} \mathrm{C}\left(97.5^{\circ} \mathrm{F}\right)$. Compared with the British national survey, which numbered 1,020 cases, $3.4 \%$ of the cases were hypothermic (temperature $\leqslant 35^{\circ} \mathrm{C}$, or $95^{\circ} \mathrm{F}$ ), whereas $5.1 \%$ of the British sample had temperatures at this level.
\end{abstract}

The onset of cold weather, the rising cost of heating, and the suggestions to conserve energy bring renewed interest in accidental hypothermia. The National Institute on Aging has revised its 1978 brochure (National Institute on Aging, Note 1) on the subject, and the revision has received more than its share of coverage by all facets of the press.

While we can define the condition as an abnormally low body temperature, we do not have data to indicate its prevalence, especially among the elderly, the group toward which all of the emphasis has been directed. In fact, we have to rely on the national survey of the British elderly (Wicks, 1978) for most of our data on accidental hypothermia. To do this demands caution, because (1) the heating systems in the British homes are below the quality of those in the U.S. and the British practice of keeping their residences considerably cooler than ours is widespread, and (2) the British wear more clothes and heavier clothing during the heating season than the average U.S. citizen does. Because of these factors, a survey was made during the winter of 1980 among a group of rural Kansas elderly, to determine the extent of accidental hypothermia with a U.S. sample. This paper will present the results of that survey.

\section{METHOD}

Two predominately rural counties (Riley and Pottawatomie) in Kansas were selected for study. Staff members from the Kansas State University Institute for Environmental Research accompanied teams from the Health Departments of these counties on their appointments to various towns in which blopd pressure, well-baby, and general health clinics were held. When an elderly person reported to a clinic, he was asked whether he was over 60 years of age and, if so, whether he would agree to have his temperature taken. If the replies to these questions were affirmative, the individual was appropriately identified, and not less than $30 \mathrm{~min}$ later, after he had signed a "consent" statement, his oral temperature was taken. A conventional clinical thermometer was used; however, if an individual's temperature was less than $35.6^{\circ} \mathrm{C}\left(96^{\circ} \mathrm{F}\right)$, the temperature reading was verified with an Electrotherm (low-reading) digital thermometer, TM-99.

\section{RESULTS}

The results on the 730 subjects for whom oral temperatures were taken are presented in Table 1. At the outset, the mean temperature for all subjects was $36.4^{\circ} \mathrm{C}$ $\left(97.5^{\circ} \mathrm{F}\right)$, more than a full $1^{\circ} \mathrm{F}$ below $37.0^{\circ} \mathrm{C}\left(98.6^{\circ} \mathrm{F}\right)$, the level usually taken as normal. The mean temperature by age group was at approximately this level, with the

Table 1

Oral Temperature by Age

\begin{tabular}{|c|c|c|c|c|c|c|c|c|c|c|}
\hline \multicolumn{2}{|c|}{ Oral Temperature (in Degrees) } & \multicolumn{9}{|c|}{ Age (in Years) } \\
\hline Centigrade & Fahrenheit & $60+*$ & $60-64$ & $65-69$ & $70-74$ & $75-79$ & $80-84$ & $85-89$ & $90-94$ & Total \\
\hline $37.1-37.5$ & $98.7-99.5$ & 2 & 0 & 4 & 8 & 13 & 10 & 0 & 0 & 37 \\
\hline $36.6-37.0$ & $97.8-98.6$ & 17 & 31 & 63 & 49 & 68 & 40 & 18 & 1 & 287 \\
\hline $36.1-36.5$ & 96.9-97.7 & 14 & 16 & 46 & 37 & 58 & 34 & 13 & 0 & 218 \\
\hline $35.6-36.0$ & $96.0-96.8$ & 8 & 10 & 11 & 32 & 40 & 19 & 11 & 0 & 131 \\
\hline $35.1-35.5$ & 95.1-95.9 & 1 & 1 & 3 & 8 & 9 & 6 & 4 & 0 & 32 \\
\hline $34.6-35.0$ & $94.2-95.0$ & 0 & 0 & 4 & 4 & 6 & 6 & 3 & 0 & 23 \\
\hline $34.1-34.5$ & $93.3-94.1$ & 0 & 0 & 0 & 0 & 1 & 1 & 0 & 0 & 2 \\
\hline Total & & 42 & 58 & 131 & 139 & 139 & 116 & 49 & 1 & 730 \\
\hline
\end{tabular}

Note-The mean temperatures for the various age groups were as follows: $60-64$ years $=36.4^{\circ} \mathrm{C}\left(97.6^{\circ} \mathrm{F}\right), 65.69$ years $=36.5^{\circ} \mathrm{C}$ $\left(97.7^{\circ} \mathrm{F}\right), 70-74$ years $=35.9^{\circ} \mathrm{C}\left(96.7^{\circ} \mathrm{F}\right), 75-79$ years $=36.4^{\circ} \mathrm{C}\left(97.5^{\circ} \mathrm{F}\right), 80-84$ years $=36.4^{\circ} \mathrm{C}\left(97.5^{\circ} \mathrm{F}\right), 85-89$ years $=36.2^{\circ} \mathrm{C}$ $\left(97.2^{\circ} \mathrm{F}\right)$; overall mean $=36.4^{\circ} \mathrm{C}\left(97.5^{\circ} \mathrm{F}\right) . \quad{ }^{*}$ Age not specified. 
exception of the 70- to 74-year-old group, whose mean temperature was $35.9^{\circ} \mathrm{C}\left(96.7^{\circ} \mathrm{F}\right)$.

Wicks (1978) identified two groups in his survey. Those individuals whose temperature was between $35.5^{\circ} \mathrm{C}\left(95.9^{\circ} \mathrm{F}\right)$ and $35.1^{\circ} \mathrm{C}\left(95.1^{\circ} \mathrm{F}\right)$ were considered to be "true" hypothermics. In comparing our findings with those of Wicks, we find that $13.5 \%$ of the British sample of 1,020 had oral temperatures between $35.5^{\circ} \mathrm{C}$ $\left(95.9^{\circ} \mathrm{F}\right)$ and $35.1^{\circ} \mathrm{C}\left(95.1^{\circ} \mathrm{F}\right)$; in contrast, $7.8 \%$ of our sample of 730 had temperatures in this range. The "true hypothermics" of the two surveys were similar. The Kansas sample had $3.4 \%$ with temperatures of $35.0^{\circ} \mathrm{C}\left(95^{\circ} \mathrm{F}\right)$ or less, whereas the British sample had $5.1 \%$.

\section{COMMENT}

At the outset, the lower mean oral temperature among the Kansas elderly reflects the general reduced metabolic rate that accompanies aging. Particularly interesting is the fact that the mean oral temperature remained fairly uniform for all age groups.

This lower body temperature is believed to be associated with the general "sluggishness" of the thermoregulatory system that appears to accompany the aging process. In short, as we get older we do not sweat as much in the heat, nor do we shiver or have "goose bumps" in the cold. This fact is also relevant to hyperthermia, and it should be considered when studying the causes of death during the heat wave in the summer of 1980 , in which the same general segment of the population who suffer from hypothermia also appear to have been susceptible to hyperthermia.

It should be pointed out that the temperatures reported in this paper were taken under field conditions. While the subjects were indoors, no attempt was made to control the ambient temperature of the room. In one sense, this is a shortcoming of the study; in another, it is more representative of the conditions that prevail in the clinic, hospital, nursing home, or residence. Because of this, the data may be considered a standard for interpreting the oral temperatures of the U.S. elderly. They are based on a meaningful sample of 730 and are comparable to the British National Survey.

One additional item is worthy of note. It is the opinion of the author that the qualifying adjective "accidental" that precedes hypothermia is a misnomer, because it implies a low body temperature brought about by an accident. It is our belief that there are at least three types of hypothermia: accidental, which may be used to describe the low body temperature that a seaman might exhibit when swept overboard into Lake Superior; induced, the conventional surgical protocol; and noninduced, or spontaneous, the type described in this paper. Adopting this nomenclature not only would appear more appropriate and meaningful but would also demonstrate to the lay public that lower body temperature may occur independently of the environmental temperature and without an intervening accident.

\section{REFERENCE NOTE}

1. National Institute on Aging. Accidental hypothermia: Winter hazard for the elderly (DHEW Publication No. NIH 78-1464). Bethesda, Md: Author, 1978.

\section{REFERENCE}

Wicks, W. Old and cold: Hypothermia and public policy. London: Heinmann, 1978.

(Received for publication February 26, 1981.)

\section{ERRATUM}

Solso, R. L., \& McCarthy, J. E. Prototype formation: Central tendency model vs. attribute-frequency model. Bulletin of the Psychonomic Society, 1981, 17(1), 10-11. Page 11, Column 1, Paragraph 2, Lines 4-12, the sentence should read: In order to make specific comparisons among the groups, a protected least-significant difference (1.s.d.) test for proportional means was calculated, with the following results: $\mathrm{P}_{\mathrm{f}}$ vs. $\mathrm{P}_{\overline{\mathrm{X}}}, \mathrm{t}(42)=3.47(\mathrm{p}<.001)$; $\mathrm{P}_{\mathrm{f}}$ vs. new items, $t(130)=4.50(p<.001) ; P_{f}$ vs. old items, $t(130)=1.70(p<.10)$; old items vs. $\mathrm{P} \overline{\mathrm{X}}, \mathrm{t}(130)=2.09(\mathrm{p}<.05)$; and old items vs. new items, $\mathrm{t}(218)=4.23$ $(\mathrm{p}<.001)^{1}$ 